\title{
Making Sense of the Diversity of Ethical Decision Making in Business: An Illustration of the Indian Context
}

\author{
Taran Patel \\ Anja Schaefer
}

\begin{abstract}
In this conceptual article, we look at the impact of culture on ethical decision making from a Douglasian Cultural Theory (CT) perspective. We aim to show how CT can be used to explain the diversity and dynamicity of ethical beliefs and behaviours found in every social system, be it a corporation, a nation or even an individual. We introduce CT in the context of ethical decision making and then use it to discuss examples of business ethics in the Indian business context. We argue that the use of CT allows for a theoretically more sophisticated treatment of culture in ethical decision making and thus the avoidance of some common problems with existing cross-cultural studies of business ethics. In our discussion, we raise questions about the compatibility between management systems and processes created in one context and ethical behaviours in another.
\end{abstract}

KEY WORDS: code of ethics, Douglasian Cultural Theory, methodological individualism, shareholder approach, stakeholder approach, culture and ethics

ABBREVIATIONS: CT: Cultural Theory; CSR: Corporate Social Responsibility; GLOBE: Global Leadership and Organizational Behaviour Effectiveness; GGT: Grid-Group Typology; SEWA: Self-Employed Women's Association; ONGC: Oil and Natural Gas Corporation Limited; BHEL: Bharat Heavy Electricals Limited; NTPC: National Thermal Power Corporation; UN: United Nations

\section{Introduction}

This article employs Douglasian Cultural Theory (CT) to provide an account of cultural diversity in ethical decision making in business, focussing specifically on the Indian context. Ethical decision making has been one of the core strands of the business ethics literature and the area has seen an increased level of interest over the recent years, as witnessed by several review articles on the subject (e.g. O'Fallon and Butterfield, 2005; Tenbrunsel and Smith-Crowe, 2008). Much of the seminal work in this field has been concerned with building models of ethical decision making or behaviour, generally based on Rest's (1986) four-component model of individual ethical decision making: (1) recognition of moral issue; (2) making of moral judgement; (3) resolving to prioritise moral concerns; (4) acting on moral concerns, where each of the four components is conceptually separate. Building on such earlier study, Jones (1991) offered an integration of earlier models, again mostly based on Rest's (1986) four components and adding a specific focus on the 'moral intensity' of the issue under consideration. In their recent review of the literature, Tenbrunsel and Smith-Crowe (2008) add a further dimension by distinguishing between moral and amoral decision making, and stressing that either can lead to ethically acceptable or unacceptable decisions. They argue that there is no linear, compelling link between moral awareness, moral decision making (i.e. decision making where the actor is aware of the moral implications of the decision to be taken) and the ethicality of the outcome. Figure 1 shows a synthesis of these models to frame some of our discussion below. It is not intended to be a testable model, and no a priori assumptions are made here about a linear, rational process of ethical decision making.

Ethical thought has been divided on the universality or otherwise of ethical maxims. Much Western moral philosophy holds ethical principles to be universal and indivisible. Once an ethical principle has been demonstrated to be valid it is held to be 


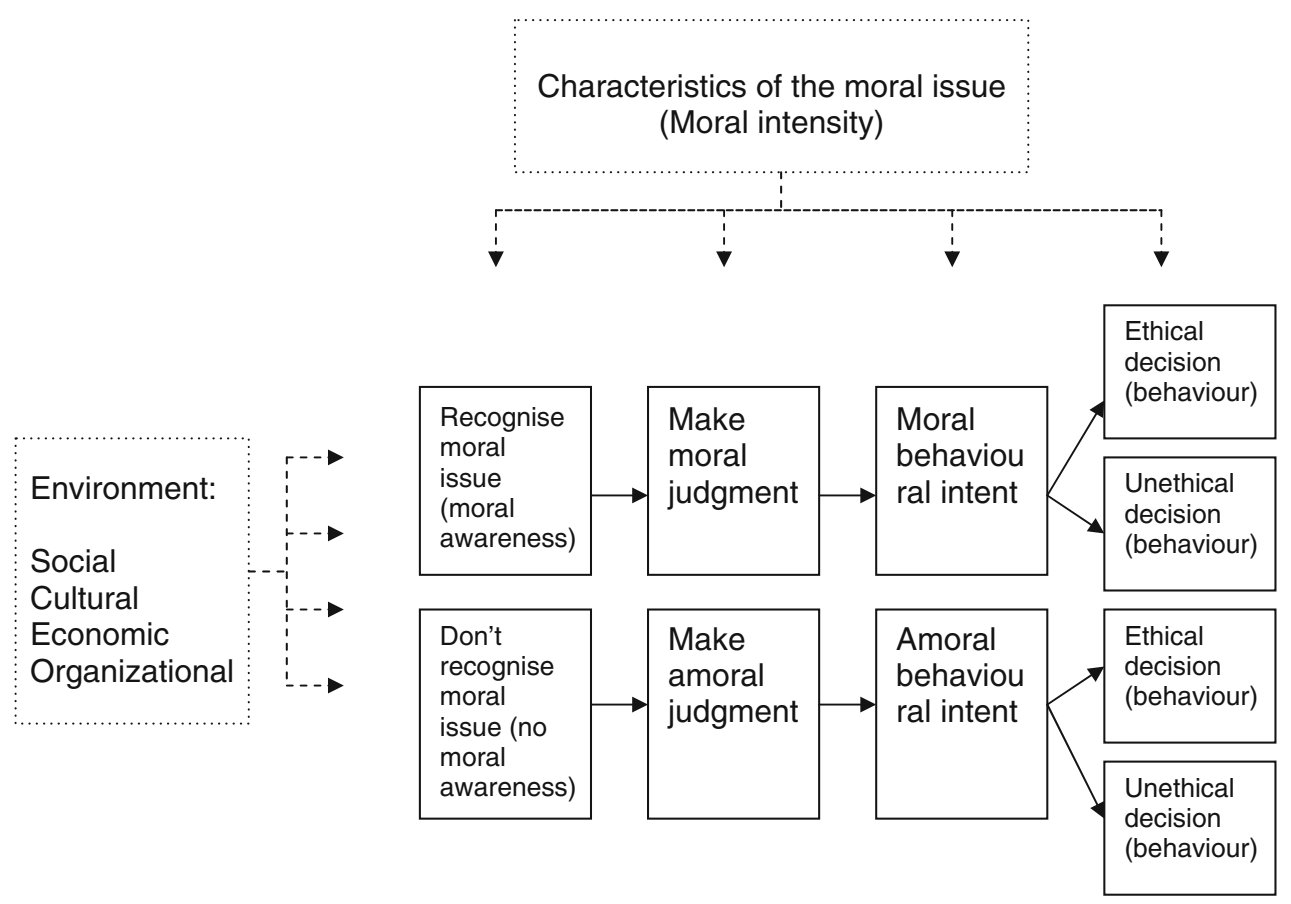

Figure 1. Synthesis of models of ethical decision making (adapted from Jones 1991 and Tenbrunsel and Smith-Crowe 2008).

true under all the circumstances. From this perspective, business ethics is seen (often implicitly) as a universal and indivisible value system that should guide the action of one and all in a corporation (Crane and Matten, 2007; Velasquez, 2002).

Contrary to this view stands ethical relativism which takes ethical norms to be socially constructed and highly dependent on context. Taken to extremes, this view holds that there are as many ethical stand points as there are humans and that everybody ultimately has their own ethical standards (Crane and Matten, 2007; Velasquez, 2002). From this perspective, business ethical values, like other aspects of business, are seen as dependent on national culture or national origin (Alas, 2006; Ringov and Zollo, 2007; Vitell and Hidalgo, 2006, etc.), gender (McCabe et al., 2006), individual value systems (see Steenhaut and Kenhove, 2006), size of the employing firm (Longenecker et al., 2006) and other similar criteria.

In this article, we do not propose to add to the ethical universality versus ethical relativism debate, nor are we concerned with ethical principles as much as with ethical behaviours. We approach the question of diversity in ethical behaviour not so much from a moral philosophy but from a CT angle. In doing so, we argue that choices about specific ethical behaviours do not depend on a static and universal set of rules but that ethical value systems are also not infinite, i.e. there are not as many varied ethical value systems as there are social systems. By linking ethical approaches to the four solidarities proposed by $\mathrm{CT}$, we attempt to provide a systematic tool to make sense of the diverse ethical behaviours we observe in any social system. In other words, in the tradition of cultural theorists, we believe in the essential pluralism and constrained relativism of ethical behaviours. (Business) ethics in this understanding are not a set of normative values to dictate behaviour but rather a dynamic set of world views that guide action within a certain context and which can evolve when the context changes.

Several studies have examined cross-cultural differences in ethical decision making, specifically, and business ethics more generally, and concluded that on balance, national culture had an impact (O'Fallon and Butterfield, 2005; Tenbrunsel and SmithCrowe, 2008). A number of such studies study the impact of culture using Hofstede's value dimensions. Thus Husted and Allen (2008) found that the 
perception of moral problems, moral reasoning and behaviour all depended partly on individuals' levels of individualism and collectivism. Ringov and Zollo (2007) claimed that ethical decision making, especially in the social and environmental context is dictated by national culture and that companies based in countries characterized by higher levels of power distance, individualism, masculinity and uncertainty avoidance exhibit lower levels of social and environmental performance. Davis et al. (1998) found that judgements of moral concern and judgements of immorality varied significantly with socio-cultural region along Hofstede's value dimensions but that cultural differences were moderated by the ethical issue depicted. They concluded that social consensus had the greatest effect on judgements of moral concern and judgements of immorality, and that socio-cultural differences were moderated by the type of ethical issue. In a similar vein, Vitell and Hidalgo (2006) found that the perceived importance of business ethics and social responsibility varied depending upon country of residence, with a US sample showing somewhat higher perceived importance of ethics and social responsibility than a similarly constructed sample in Spain. The authors concluded that companies of American national origin show higher levels of ethicality than the Spanish companies. Alas (2006) also argues that national culture can be used as a predictor for ethically desirable practices. While such findings would suggest that culture does, indeed, play a role in ethical decision making, there appear to be three common problems with existing studies of the impact of culture on business ethics. We argue that these problems result from applying limited, static conceptions of culture to business ethics. We also propose $\mathrm{CT}$ as an alternative to these static conceptions of culture. The three problems are as follows:

(1) The first of these problems concerns the kind of national stereotyping which results from a static view of the impact of national culture on ethical values and behaviours. The kind generalisations about levels of ethicality in specific national contexts that have been made in some of the studies cited above would seem too broad to be true for any nation. Apart from the fact that the findings cited above (see Vitell and Hidalgo, 2006) beg the question why firms from all national origins, including American, have at various times been accused of unethical practices both at home and in their foreign subsidiaries, greater reported importance of business ethics may be a function of a variety of factors, including the national business system and practices and the level of regulation. Such differences may also be an artefact of the research instrument, and do not necessarily imply more ethical behaviour or even greater ethical awareness.

(2) A second problem stems from a focus on national culture to the detriment of other aspects of culture. An individual's national culture or country of residence is not the only socio-cultural context that needs to be considered. Individuals will be influenced by different and inter-linking aspects of their environment: the immediate neighbourhood, the workplace, the family, participation in social groups, etc. (Ferrell and Gresham, 1985; Trevino, 1986). We contend that these situational factors can be just as important as national culture in influencing ethical behaviours and focussing solely on national culture is likely to produce an overly narrow picture. For example, Westerman et al. (2007) found that the influence of peer culture on individuals' ethical decision making was greater than that of national culture (although national culture seemed to mediate peer influence) and Srnka (2004) found that, while national culture had a stronger impact on the affective dimension of ethical decision making, organisational culture had a stronger impact on the behaviour dimensions.

(3) A third problem arises out of an - explicit or implied - assumption that companies can or should modify their behaviour when they do business in different countries (e.g. Moon and Woolliams, 2000; Scholtens and Dam, 2007). Under this assumption, an American firm doing business in India would adapt its ethical behaviour to match with Indian standards and while doing business in Germany it would again adapt its behaviour to 
German preferences. However, what constitutes these so-called 'Indian' preferences or 'German' preferences is not clearly understood. Are we to assume that countries, as a whole, are homogenous in their ethical preferences? Once again this is such a broad generalisation that it is unlikely to be true for any nation. Besides, where does this hypothesis leave the firm in question? Would it be correct to assume that it has no preferences of its own and simply adapts to every new country it deals with? Furthermore, will companies be able to adapt their ethical preferences and behaviours at will to match with those of the host country?

We believe that these three problems can all be at least partly attributed to a limited conceptualisation of culture. On the one hand, much business ethics writing does not appear to give much thought to any cultural embeddedness of ethical behaviour at all. In the universalist tradition, principles of ethical business behaviour seem to be taken to stand above and independent of cultural context. On the other hand, where cultural variation in approaches to business ethics has been considered, it is often based on static views of national culture, such as that proposed by Hofstede (1984). A notion that some national cultures are somehow more attuned to business ethics than others (as discussed above) would seem to stem at least in part from such a perspective. Yet, national cultures are neither homogenous nor unchanging (Patel, 2005, 2007; Usunier, 1998) and attempts to correlate quantitative measures of national cultural differences against ethical preferences seem problematic from this perspective. A straight-forward relationship between national culture and ethical versus unethical practices is put in question by the studies such as Schepers (2006), who demonstrates the presence of different sets of ethical values within a single American corporation, and Resick et al. (2006), who found that each of four dimensions, namely character/integrity, altruism, collective motivation and encouragement were universally endorsed as being important for effective ethical leadership, yet that respondents from different cultures varied significantly in the degree of endorsement for each dimension. In contrast to a static conception of culture focussed mostly at the national level, we propose to use a more dynamic approach to culture, namely, CT. Although we will focus later in this article on the national context of India, we argue that explanations offered by CT are independent of social scale and would equally apply to socio-cultural influences at the corporate and/or the individual level. Since the CT approach is not limited by scale or specific national context, we further argue that, if the general direction of our explanation is true for India, it would be true for other nations as well.

The remainder of this article is organized as follows. In the next section, we provide a discussion of CT and then discuss its application to ethical decision making. In the following section, we examine ethical decision making and behaviour in the Indian business context from the point of view of CT. At this stage, it needs to be noted that, although we are not aware of other studies explicitly linking CT to ethical behaviours in businesses, the concept of dynamic and ever-changing ethical preferences is not new in itself. An attempt to propose a dynamic view to business ethics was made by Victor and Cullen (1987), who explored the notion of ethical climates by employing a $3 \times 3$ matrix, creating nine distinct climates. Similarly, Lovell's (2002) study showed that there could be a fluid classification of the behaviours displayed by the principal actors as their respective ethical scenarios unfolded and that a simple singular categorisation was inappropriate. However, we believe that $\mathrm{Ct}$ can provide a more systematic theoretical framework for such analyses.

\section{Douglasian Cultural Theory (CT)}

Mary Douglas introduced the Grid-Group Typology (GGT) in Natural Symbols (Douglas, 1970) and expanded it in Cultural Bias (Douglas, 1978). Since then, the GGT has been applied to study different fields including ecology (Douglas and Wildavsky, 1983), risk perceptions in organisations such as hospitals (Rayner, 1986), and work-place crime (Mars, 1982). The Grid Group Typology or CT as it came to be known later, explains that people structure their ideas about the natural and social world in a way which is compatible with the social structure they find themselves in at a point in time. 
In other words, there is a relationship between the concepts people use to understand the world and the systematic social constraints or social structures, these people are exposed to. The overall aim of CT is to provide a framework within which a cultural analyst may consistently relate differences in social structures to the strength of the values that sustain them (Gross and Rayner, 1985).

Douglas (1970) explains that in order to classify cultures two social dimensions can be used: 'Group' and 'Grid'. 'Group' is the horizontal axis, and represents the extent to which people are restricted in thought and action by their commitment to a group, i.e. a social unit larger than the individual (Gross and Rayner, 1985). A high score on the 'group' axis means that individuals understand themselves to a large extent as members of a group and spend a lot of their time interacting with other group members. Their thoughts, beliefs, values and actions are both enabled and constrained to a very large extent by group norms and going against the norms of the group is considered uncomfortable, risky and undesirable, both by individuals and the groups of which they are members. At the other end of the scale, a low score on the 'group' axis means that people define themselves first and foremost as individuals and tend to act on their own behalf, rather than that of a group. Their thinking, beliefs, values and actions are less strongly enabled and constrained by group norms. Unlike high group scorers, low group scorers also tend to consider themselves members of more than one group and do not rely upon any single significant group for support and belonging. Individuals with a low group score are generally thought to act in a more competitive, entrepreneurial way of life (Gross and Rayner, 1985), whereas individuals with a high group score are more deeply committed to a group, therefore less likely to compete with other group members and considering their choices to be more strongly circumscribed by group customs and tradition (Douglas, 1996).

'Grid' is the vertical axis and it represents the extent to which people's behaviour is shaped and constrained by their role and status in the larger social system (Gross and Rayner, 1985). A high grid score occurs when social roles are distributed on the basis of explicit social classifications based on criteria such as sex, colour, position in the hierarchy, holding a bureaucratic office, descent in a senior clan or lineage, or point of progression through an agegrade system (Gross and Rayner, 1985). According to Mars (1982), a high grid score means that individuals experience less autonomy in their thinking, values and decision making, as much of what individuals can do is prescribed by the social position they occupy. It also means that social interactions tend to based on position and hierarchy, rather than reciprocity. At the other end of the spectrum, a low grid score means that individuals are relatively less constrained by social position and hierarchy and formally defined criteria, such as those mentioned above, play a less important role in shaping and constraining individuals thinking and decision making ability. The ability to shape decisions is less strongly tied to formal social roles and the focus tends to be more on negotiation between different parties concerned.

A matrix constructed from high and low group and grid scores results in four quadrants, which, correspond to four cultural patterns.

\section{Low grid-low group}

The cultural pattern characterized by low grid and low group scores is the competitive solidarity. Competitive solidarity, according to Gross and Rayner (1985), allows its members maximum options for negotiating relationships and changing allies. Douglas (1996) and Coyle and Ellis (1994) stress that in such a culture, boundaries are provisional and subject to negotiation. Under this cultural pattern, individuals enjoy a lot of spatial and social mobility and tend to be valued for their own accomplishments and actions. Ancestry, history, family lineage or past are of low importance. Individuals who are members of such a culture do not tend to appreciate external constraints on their behaviour and place few constraints on others. Self regulation, mutuality, and the respect for the rights of others are normally highly valued in such cultures and competitive solidarity is often associated with a free market economic organisation. According to Thompson (1996), people operating under competitive solidarity tend to apply substantive rationality when analysing and assessing issues, i.e. they tend to focus on outcomes rather than processes. 
High grid-high group

Commonly referred to as the 'hierarchical solidarity', this is a tradition-based cultural pattern in which people know their place, but in which that place might evolve with time (Gross and Rayner, 1985). People operating under this cultural pattern tend to value security and show a preference for set procedures and rules. This culture is generally averse to overt competition and allows only restricted and carefully controlled social mobility (Gross and Rayner, 1985). In hierarchical solidarity, both compulsion and inequality can be observed. There are unequal roles for unequal members and deference towards those that are perceived as being in a higher position than others (Coyle and Ellis, 1994). Rayner (1982) and Schwarz and Thompson (1990) argue that this kind of a culture tends to be oriented towards processes and is more concerned with procedures and the proprieties of who does what rather than with the outcomes of these processes and procedures.

\section{Low grid-high group}

This is termed 'egalitarian solidarity' in the CT literature and refers to a culture in which the main preoccupation of the members, according to Gross and Rayner (1985) is to reinforce external group boundaries. All other aspects of interpersonal relationship are ambiguous and open to negotiation. According to Douglas (1986), this solidarity is characterized by small group, face-to-face interactions, participative decision-making and a network of reciprocal exchanges. Further, this culture applies few constraints on its members who are bound together by a high group consciousness and voluntary respect for the concern of others (Coyle, 1997).

\section{High grid-low group}

Termed 'fatalistic solidarity' in the CT literature, Gross and Rayner (1985) define this cultural pattern as one in which members are socially classified into different classes according to formal and static criteria, such as race, hierarchical status, gender, etc. and their behaviours are strongly regulated by these classifications. Such a cultural pattern emerges when people in strongly hierarchical structures have been excluded from decision-making. According to Gross and Rayner (1985) people are not normally in this category by their own free will, they are coerced into it. In this type of culture, the individual has little choice how she spends her time, whom she associates with, what she wears or eats, or where she lives or works (Coyle and Ellis, 1994). People in a fatalistic culture experience the social isolation of the competitive solidarity (low-grid-low group) but without its autonomy. Similarly, they experience the control typical of 'hierarchical solidarity' (high-gridhigh-group) but without the group support.

The four solidarities, or cultural patterns, as proposed by CT should not be taken as static categories. Rather, every social system should be seen as a dynamic one in which the four solidarities are constantly competing for dominance, with none ever achieving it (Thompson, 1996). If different ethical behaviours and preferences are associated with different cultural patterns, as has been argued by Patel (2006), and if, as argued in CT, all four solidarities can be observed in every social system, this implies that every social system (e.g. a nation, a corporation, even an individual) is ethically plural or diverse. It is diverse because these four ethical strategies coexist in it. As the four solidarities incessantly compete for dominance, the social system is in a state of constant disequilibrium. In the next section, we will consider how different cultural patterns may impact on ethical decision making.

\section{Understanding ethical decision making using CT}

In the introductory section of this article, we have identified the several key elements of ethical decision making (summarized in Figure 1):

- Ethical decision making is influenced by the intensity of the moral issue and influences in the external environment;

- The process of ethical decision making includes recognition or non-recognition of the moral issue (moral awareness or non-awareness); making of moral or amoral judgement; moral or amoral behavioural intent; 
- Both moral and amoral decision making lead to either ethical or unethical decisions as there is no linear connection between behavioural intent and actual behaviour.

Arguably, all of these elements can potentially be influenced by the cultural pattern or solidarity under which people are operating. Although Jones (1991) does not use CT, it may well be argued that the cultural pattern is one of the key aspects of the external environment. We can further argue that the way in which characteristics of moral issues will be perceived and whether or not managers understand an issue as a moral one will differ between cultural patterns. That is to say, one of the key issues in ethical decision making would seem to relate to the way in which managers perceive and interpret information about the external consequences of business activities. Depending on what type of information is attended to or rejected and how this information is interpreted, different ethical decisions are likely to be made. CT addresses this issue through its discussion of multiple rationalities.

A crucial aspect of human behaviour is thought to be the way in which information is attended to or rejected (Thompson, 1996; Thompson and Wildavsky, 1986). It is clear that people cannot pay full attention to all incoming information at all times. They can only pay partial attention, selecting some phenomena in and rejecting other information that falls outside their organized perception. Thompson and Wildavsky (1986) link four different styles of information rejection to the four solidarities proposed by CT. Networking is the rationality that, according to Thompson and Wildavsky (1986) best suits the competitive solidarity. Wynne and Otway (1982) have pointed out that members of this solidarity try to shift the really vital discussions away from the formalized information-handling system and on to the informal, 'old boy' networks. Thompson and Wildavsky (1986) have described this strategy as individualist manipulative. Building on this, we suggest that when faced with an ethical dilemma, the competitive solidarity tends to choose a solution that meets its own interest and that of the members who form part of its network. However, since members of the competitive solidarity tend not to apply pressure on themselves to conform to group membership, nor can they oblige others to conform to themselves, there is very little organisational glue to bind different members of this solidarity together. Hence, an external objective such as focus on profitgeneration both for the corporation as well as the individual may be the only way they can rally support from others. This may suggest that competitive solidarity would have a preference for a shareholder approach to ethical decision making in business, as has been argued by Patel (2006).

Paradigm Protection, according to Thompson and Wildavsky (1986) is the rationality most congruent with the hierarchical solidarity. The hierarchical cultural pattern is not resistant to change itself, but to those changes that threaten its hierarchical structure and order. It is resistant to any change that causes information to spill out of its prescribed channels that disrupts set procedures or raises questions about the paradigms on which the whole hierarchical structure rests. Paradigm protection is an information rejection style which is often diffused and depersonalized. "When it is forced out into the open, it is usually swathed in an aura of altruistic self-sacrifice. It is about collectivist manipulation" (Thompson, 1996, p. 42). Building on this, one might say that since members of the hierarchical solidarity are focussed on maintaining existing paradigms, it is important for them to understand and respect the way different people or groups are prioritized, with maximum attention paid to the needs of those high on the priority list. Hierarchical solidarities may thus show a preference for a stakeholder approach, where stakeholders are differentiated into primary and secondary and different expectations can be attended to, as well as hierarchical differences between stakeholder groups maintained.

Expulsion is the rationality that, according to Thompson and Wildavsky (1986), would seem to relate best to the egalitarian solidarity. The egalitarian solidarity is thought to take a more uncompromising and fundamentalist stand on what it believes in as compared to other solidarities. It concentrates on defending its boundary, protecting 'vulnerable insiders' from 'predatory outsiders'. It does this by rejecting any threatening information. Egalitarian groups "....do not negotiate and refuse to compromise with the wider society. They cannot manipulate anyone except their own members, who, of course do not see this as manipulation" (Thompson, 1996, p. 42). Members of this sort of 
group sustain themselves with a collective survival strategy. The egalitarian solidarity, like the hierarchical solidarity, may therefore show a preference for a stakeholder approach to business ethics (Patel, 2006). However, unlike hierarchical solidarity which prioritises primary over secondary stakeholder, members of the egalitarian solidarity would focus on defending the interests of in-members by prioritising them over those of the outsiders, without discriminating between in-members.

Risk Absorption, according to Thompson and Wildavsky (1986) would be the rationality associated with fatalistic solidarity. To the fatalistic mindset, 'life is like a lottery' (Thompson, 1996, p. 41). The individual does not control anything that happens to $\mathrm{him} /$ her. "Strategy is really too strong a word to use for the way of coping that is seen as the appropriate response in this sort of situation. It is merely about self-preservation" (Thompson, 1996, p. 41). If people operating under a fatalistic cultural pattern feel threatened or challenged about their survival, they are likely to make decisions in such a way as to ensure their self-preservation. People operating under fatalist solidarity may therefore be expected to make ethical decisions on an ad-hoc and therefore probably inconsistent basis. Note that 'ethical' in this sense relates to the way in which individuals think about right or wrong, not to what one might call the 'right' moral decision by some universalist standard.

The above considerations may explain why managers operating under different cultural patterns may perceive and attend to information about moral issues differently. This is to say, different solidarities or cultural patterns may lead to different perceptions of an issue's moral intensity (the characteristics of the moral issue), to different levels of moral awareness (recognition of an issue as a moral one) and hence to different moral judgements. We now argue that cultural patterns may also explain why both moral and amoral decision making processes may lead to decisions that are considered either ethical or unethical. In other words, CT can shed some light on why some managers choose to use methods that might be seen by others as unethical, although they have other options in order to achieve their corporate goals. For this purpose we need to take a closer look at the likely behaviours of the four solidarities. Members of each of the four solidarities are bound by their rationality and world views to the other members of the solidarity. Allegiance to any one solidarity means a betrayal of the other solidarities (Douglas, 1996; Pendergraft, 1998; Perry and Peck, 2004). When individuals identify themselves as a member of a certain solidarity (note that this identification may well be implicit and unconscious), they pledge their allegiance to that solidarity and its way of life. This allegiance is questioned in the face of a threatening or challenging situation. However, the more the allegiance is questioned, the more individuals may revert to their solidarity for support and resist conversion.

Individuals often tend to get so influenced by one way of life that they fail to see the merits of any other way of life. As Douglas (1996) points out, each solidarity has its merits and they are interdependent, so that each solidarity needs to coexist with others for its survival. Patel (2005) argues that the competitive solidarity needs the hierarchical solidarity so as to prevent it from falling into total chaos. The competitive solidarity, if left by itself can become so focussed on results that it tends to undermine all controlling rules and regulations. On the other hand, the hierarchical solidarity, if left to its own means, can get so obsessed with rules and regulations that it would shut out all opportunities for growth and progress. This interdependence of the two active solidarities has also been documented by Williamson (1975). Despite the general understanding that solidarities need one another to survive, there is nonetheless a tendency for members of all solidarities to stick to their own ways of life. This leads to behaviours that might be seen by others as being unethical. For example, although the competitive solidarity is entrepreneurial and seeks out opportunities for growth and development, taking these tendencies to the limit can lead to a compromise on rules and cutting corners to achieve goals. Although members of all solidarities tend to appreciate the creative drive of the competitive solidarity, they (especially members of the hierarchical solidarity) might, nonetheless, view its tendency to compromise on rules and regulations as being unethical. This is one reason (there may be others but those are beyond the scope of this article) why moral behavioural intent can nonetheless lead to decisions which are considered unethical by others.

A related question then becomes how we might explain inconsistency or changes in people's ethical 
behaviour. We argue that such changes are often dynamic rather than erratic and that, as a dynamic framework, CT can provide useful answers to this question. Thompson (1996) explains that even a tiny behavioural shift that crosses the boundary of a solidarity leads to a change in the solidarity-based affiliations of an individual. On the other hand, a larger behavioural shift within the boundary of a solidarity leave the affiliations of the individual unaltered. This reveals the dynamic nature of the solidarities. Each of the four solidarities is in a state of dynamic disequilibrium and therefore applies pressure on individuals to join them. There is therefore, a constant rivalry between the different solidarities to attract as many adherents as possible. Furthermore, Thompson $(1997 \mathrm{a}-\mathrm{c})$ argues that cultural dynamics are independent of social scale. This means that if actions fall into a number of distinct spheres, the same individual could be a member of different solidarities in different contexts. These considerations can help us to explain the differing ethical behaviours of an individual in different social contexts.

In this and the previous section, we have given an overview of CT and how it can be used to explain and analyse ethical behaviours in business. In the following section we explore examples from the Indian business world using the theoretical considerations put forward above. For the purposes of this discussion we take corporate social responsibility (CSR) activities to be a manifestation in part, at least, of ethical decision making, although we recognise that factors other than ethical considerations enter a firm's CSR stance and activities.

\section{Ethics, CT and the Indian business context}

We begin this section with a brief historical overview of the ethical context in Indian business. Kanagasabapathi (2007) provides an account of how the ethical system in place for thousands of years made ancient India a sought after country to trade with. Citing several ancient manuscripts and notes of travellers, he writes that Indian businessmen were perceived as fair, kind, law-abiding citizens who were considerate to foreign merchants and ethical in their practices. Kanagasabapathi also describes the fall of this system with foreign invasions in the eighteenth century. He contends that colonial rulers replaced past ethical and administrative systems with their own ones. After independence, the new government opted for Western economic and administrative systems. Superimposing systems that have naturally emerged in a society over past centuries with foreign systems is thought not to be good for that society (Korten, 1998).

According to Balasubramanian et al. (2005) several different ethical approaches have co-existed in India in more recent times: (1) The Gandhian Model, which stresses voluntary commitment to public welfare based on ethical awareness of broad social needs; (2) the Nehru Model, which emphasises state-driven policies including state ownership and extensive corporate regulation and administration; (3) the Milton Friedman Model, according to which corporate responsibility primarily focuses on owner objectives (Friedman, 1970) and (4) the Freeman Model, which propagates stakeholder responsiveness. Like in every ancient civilisation, the business ethics movement in India has also been influenced by various historical and political factors: (1) a strong religious tradition encouraging business benevolence, (2) businesses supporting nationalism in the first half of the twentieth century and (3) a strong affiliation with leaders, both in business and politics (Sundar, 2000). While the strength of Indian traditions provides an underlying ethos that reinforces an awareness of the social and ethical responsibilities of business, many experts are worried that modern business practices are likely to erode this (e.g. Chakraborthy, 1997; Kanagasabapathi, 2007).

Within the context of contemporary India, let us now explore the dynamicity and diversity of ethical practices using the CT framework. This will illustrate how different solidarities vie with each other in influencing Indian business practices and ethical decision making. The Indian context is a particularly interesting and pertinent one because in the past few decades, India has emerged as the world's second largest market with a fast growing economy. Further, India has recently been adjudged as a top off-shoring location (Kearney, 2004). The growing world focus on India demands that a better understanding of values and ethical practices in India be generated.

The examples that we discuss in this section cover a wide variety of businesses, including trade unions, 
cooperatives, regular profit-making businesses, and public sector as well as private sector companies. In so doing, we answer the call of recent researchers (see Unerman et al., 2007) who stress the need to study the ethical practices of a wide variety of companies and business entities in order to develop a more comprehensive understanding of business ethics beyond large private corporations.

We begin by looking at the values that have guided the creation and day to day functions of two not-for profit organisations, SEWA (Self Employed Women's Association) and the AMUL milk cooperative. SEWA (Self Employed Women's Association) is a trade union of poor, self-employed women in the state of Gujarat in West India. It was founded in 1972 in Ahmedabad by Elaben Bhatt, a staunch Gandhian and freedom fighter. SEWA's initial activities included buying handmade products from rural women and selling them in local and foreign markets. The profits made on selling these products were then distributed among the associations' members. In so doing, SEWA attempted to give some economic power to rural women and also to enhance their sense of self-reliance and dignity. The values cherished by SEWA seem to be those consistent with Gandhi's policy of altruism, which implies doing good for the poorest of the poor and protecting the weak. Following these Gandhian principles, SEWA attempts to prepare poor, rural and unemployed women in India for full 'emploreliance'. Full employment for SEWA means employment whereby workers obtain work security, income security, food security and social security. By self reliance they mean that women should be autonomous, self reliant, both economically and with regards to taking decisions in their personal lives. In so doing, SEWA hopes to reduce the gap between these rural unemployed women and other members of society. ${ }^{1}$ This desire to reduce the gap between the different segments of society hints at an egalitarian culture (Patel and Rayner, 2008a).

Another example of a business entity operating on Gandhian principles of equality, protection and empowerment of the poor is that of Amul Milk Cooperative. Amul, one of the largest producers of raw milk in the world (6.5 million kilograms per day) was created as a cooperative of 2.5 million small milk producers in 12,000 villages in the western state of Gujarat. It is now also the largest food company in
India. Amul's creation in 1946 was the result of the struggle of small milk producers in the western state of Gujarat in pre-independence India against two major challenges: (1) the souring of milk due to heat and long distances that these milk producers had to travel in order to get to the buyers (2) manipulation by the middlemen thereby leading to fluctuating and low incomes for milk producers. The founders of Amul included freedom fighters and followers of Gandhi. This had a major impact on the values imbibed among the members of this association. Today, Amul has an annual turnover of US \$1050 million (2006-2007) and has entered overseas markets such as Mauritius, UAE, USA, Bangladesh, Australia, China, Singapore, Hong Kong, and some African nations. ${ }^{2}$ The inspiration behind Amul's creation was the desire to protect the interests of both consumers and milk producers. By providing high quality and cheap products to the Indian population, it hopes to serve the consumers. However, its primary focus has always been to provide a platform for fair trade to the small milk producers in India. Amul buys milk from these small milk producers at a fair price and shares the profits generated from marketing the milk and milk products with them. This arrangement offers an incentive to the milk producers to increase production and use modern-day dairy techniques to enhance productivity, while lowering costs. Since protecting the local milk producers from the 'predatory' middlemen and other agencies that may exploit them seems to be the prime focus of Amul, it exhibits characteristics of an egalitarian culture (Patel and Rayner, 2008a).

The two examples of SEWA and AMUL seem to show clear evidence of a domination of egalitarian solidarities among the founding members and current adherents. There is an evident desire to strengthen group ties and mutual support, while reducing power and income differentials based on size and status. Let us now see a different set of examples.

Like Gandhi, Nehru also believed in addressing the needs of the poor masses of India. However, unlike Gandhi's policy of altruism, Nehru supported the policy of nationalisation. He was a strong supporter of the socialist approach, wherein the state controlled the companies so as to ensure the good of the masses. This system attempted to protect the 
rights of less privileged people. However, one of its undesirable effects was the emergence of a highly bureaucratic command economy ('license raj'). Mathias (n.s.) explains that this replaced the control of the British empire with state control, thereby hampering the entrepreneurial spirit. Since this implies both compulsion and inequality, we are essentially referring to the strategies of the hierarchical solidarity. This system led to a dominance of large, bureaucratic state-run enterprises. It is also argued that a lack of free competition led to a high level of corruption both in the state-run enterprises and in organized labour. Mathias (n.s.) contends that in a situation of very little economic competition different players might resort to unethical practices. He uses this argument to explain the total dearth of ethical practices in Indian businesses after its independence and the low emphasis on quality of products. In this, essentially socialist economy, the only trade allowed was with similar socialist economies such as Russia and Eastern Europe where again the emphasis was on state-owned companies producing products in large quantities but of low quality. Under such an approach one might say, different stakeholders had a role to play: the industry, the public (both affluent as well as the common man) and also the government. However, there was clearly a hierarchy of priorities in this system. The government was the all powerful stakeholder, which privileged a few companies by granting them licences to operate. The consumers, if affluent, could afford almost anything, while common people would have to wait their turn, sometimes for several years for basic amenities such as cooking gas, telephone services etc.

Such a hierarchical culture which favours the stakeholder approach was not seen only in postindependence India. It can also be seen in contemporary India but manifested differently. Over time, large companies, while focussing on profit-making have learnt to prioritise their stakeholders as recipients of their corporate social responsibility and philanthropic activities. For example, ONGC (The Oil and Natural Gas Commission of India) and Tata Steel generally prioritise the communities they operate in through community development projects. On the other hand, Hindustan Lever Limited focuses on creating income-generating opportunities for under-privileged rural women through its Shakti project (Gupta, 2007). Organisations such as the National Thermal Power Corporation (NTPC) and Bharat Heavy Electrical Limited (BHEL), both signatories of the UN Global Compact focus on training their employees, development of the rural communities where their plants are located and have also actively contributed to reconstruction of areas affected by Tsunami and other natural calamities (Gupta, 2007, for a detailed discussion see Patel and Rayner, 2008a).

Other Indian companies have come up with innovative ideas to reach out to those stakeholders who have so far remained locked out. The 'simputer', a low-cost internet reading device, which could provide much needed data in remote regions that lack communication infrastructure, or an electronic diagnostic device for 'in the field' paramedics are examples of products recently developed in India based on this idea (Jose et al., 2003; Sankaran, 2003 cited by Prahalad, 2004a, b). Another example of how a company can improve its own performance by focussing on stakeholders at 'the bottom of the pyramid' (see Prahalad, 2004a, b) is that of Aravind Eye Care in the south of India. Through a series of process innovations, this company provides cataract operations to poor Indian masses at the spectacular rate of $\$ 25-30$, instead of $\$ 3000$, which is the normal rate in most developed countries. As a result, Aravind Eye Care has now become one of the largest eye care provider in the world performing over 200,000 eye surgeries a year (Prahalad, 2004a, b). Although at first glance, the efforts of Aravind Eye Care seem altruistic in nature because they address the needs of stakeholders otherwise excluded from the benefits of scientific progress, they are also in the interest of the company because in addressing the needs of such stakeholders, it is creating a 'niche' market for itself.

The examples discussed above demonstrate the ethical strategies of the hierarchical solidarity because when companies think about the interests of multiple stakeholders, they are demonstrating their highgroup characteristics. However, they also prioritise among their different stakeholders. For example, some companies such as Infosys, choose to focus on improving conditions for their internal stakeholders i.e. their employees. Others prioritise the needs of specific groups of external stakeholders. Such differentiation among stakeholder may be indicative of 
high grid characteristics, which, combined with the high group characteristic discussed above, would suggest that these companies are characterized by the hierarchical solidarity.

Thus far, we have provided examples of Indian business organisations whose ethical decision making and CSR strategies seem to be dominated by egalitarian and hierarchical cultural patterns. This does not mean that the other two cultural patterns, i.e. the competitive and the fatalist solidarities, are not to be observed in India.

In the early 1990s, under pressure from the World Bank, India started moving towards a free economy. A free market economy is thought to be geared towards consumer preferences and sovereignty. In line with this, Indian consumers started demanding better quality at lower prices, forcing companies to be more efficient and to provide better quality goods at lower prices than competitors. While the consumers arguably attained more power in this free market economy, shareholders also became more demanding. Companies needed to keep both shareholders and consumers happy in the face of tough competition from global companies. This obliged traditional family-run Indian companies like Kirloskar (manufacturer of automotive parts, lubricants, etc.) to change the way they worked so as to become more efficient and result-oriented (see Patel, 2005). This focus on outcomes and a willingness to change in order to be more competitive indicate behaviours typical of the competitive solidarity. A good example of shareholder-focussed ethical decision making in line with a competitive solidarity is that of Reliance Industries Limited. Reliance openly claims that one of its most important social responsibilities as a business entity is to provide the best and cheapest products to its consumers and the best returns to its shareholders (Patel and Rayner, 2008a, b). This does not mean that this company has not contributed to philanthropic activities. On the contrary, it has invested millions in building hospitals, research centres, educational institutions etc. and in providing scholarships to underprivileged children, especially girls in rural India. ${ }^{3}$ Yet, the prime focus of the company remains to provide the best results to the shareholders and the best price and quality to its customers, which essentially characterises its competitive focus.

Besides the three active solidarities, in every social setting there is the fourth solidarity which tends to be scared to voice its opinion and hence is difficult to identify: the fatalist. In the Indian context, historical and social facts reveal the existence of such a group (see Bhattacharji, 1995; Elder, 1966 etc.) notably from the lower classes, that experiences isolation and is subjected to control by powerful social entities. This suggests high grid - low group circumstances. Elder (1966) has well described how the fatalistic solidarity manifests itself among the Indian workforce. He provides examples of how, instead of expressing frustration due to unexpected social changes, Indian workers adapted to it by attributing it to their fate or to God. Elder (1966) identifies three different kinds of fatalisms seen among Indians. If the determining factors of life are a God or a moral order, such as Karma, then man may be powerless in terms of the outcome of any specific action. This he terms theological fatalism. Under these beliefs, however, over a longer time span humans can shape their destiny by being virtuous, carrying out God's will, or accumulating merit. Yet, if the determining factors of life are completely arbitrary forces such as luck or happenstance, there really is nothing humans can do to shape their destiny. Elder (1966) terms this empirical fatalism. Finally, social fatalism is defined as the perceived inability to change one's social position in life. According to Elder, Hindus have a higher score on both empirical fatalism and social fatalism than other religious communities in India. We contend that an example of empirical fatalism was seen among young entrepreneurial companies during the 'licence raj'. Since these companies were subject to heavy bureaucracy, they felt constrained in this newly independent nation. Arguably this led to unethical behaviours, such as rampant corruption and bribery by companies to get orders and by consumers to secure goods (see Mathias, n.s.).

The above examples show that different businesses in India show different ethical behaviours corresponding to each of the four solidarities as proposed by CT. These examples also show that the history of ethical decision making and perceived social responsibilities in Indian businesses reflects the way in which the various solidarities co-exist and vie for domination. While SEWA and AMUL demonstrate ethical behaviours in line with an egalitarian cultural pattern, Tata Steel, ONGC, NTPC and BHEL seem to show ethical behaviours more in line 
with a hierarchical cultural pattern. We have also seen examples of ethical decision making in line with a competitive solidarity in the case of Reliance, and ethical behaviours that would seem to spring from a fatalist cultural pattern in the case of companies who felt compelled to curtail their entrepreneurship in response to the constraints imposed by the Indian government.

A discussion of the historical context also provides an intellectual and philosophical background for the adoption of different ethical strategies by different corporations. For example, the Gandhian philosophy of altruism could be seen as a precursor of the corporate moral agency approach. This also reflects the adherence to the egalitarian world view wherein every one has the same rights on the resources of the country and hence deserves to be treated equally. On the other hand, Nehru's socialist approach could be likened to a stakeholder approach wherein the stronger stakeholders get priority over weaker ones. This suggests a paternalistic type of hierarchical solidarity where a powerful state controls less powerful companies, which in turn control the products made accessible to the less powerful masses. The capitalist influence brought about by globalisation has generated an appreciation for a shareholder focussed approach which seems to sit well with a competitive solidarity. There are also examples of Indian businesses feeling repressed by other agents more powerful than themselves and where the only solution for self-preservation is to demonstrate commitment to the dictates of the 'more powerful'. This is illustrative of the fatalistic behaviour.

Before we conclude this section, one point deserves reiteration: As CT is not limited in its scope of application, what is true for one country (in this case India) should also be true for other countries, for other social entities (e.g. corporations, clubs, social activist groups, intergovernmental collaborations etc.) as well as for individuals.

\section{Conclusions}

We have argued above that four predominant types of ethical behaviours coexist in every social system, linked to the dynamic coexistence of the four solidarities or cultural patterns identified by CT. This approach allows us to go beyond static conceptions of national culture and its impact on business ethics. Through a series of examples we have shown the coexistence of the four cultural patterns and associated ethical behaviours in the current Indian business context. This would seem to raise question marks about studies that link ethical behaviour in a straightforward way to national origin and national culture. If the dynamic coexistence of different ethical strategies is observed in India, there is no reason why similar observations should not be made in other countries as well. From this perspective, generalized suggestions that managers from one national background are likely to show greater ethical awareness or come to more ethical decisions than managers from other backgrounds - as seem to be implied, by some of the studies cited in the introduction - would seem to overlook both the coexistence of cultural patterns and the dynamic nature of the impact of culture on business ethics.

An important managerial implication of our study is that it raises questions about the compatibility between management systems and processes created in one context and their impact on ethical behaviours in another. Consider the example of codes of ethics. This article raises some questions about the usefulness of codes of ethical practices that have become so popular in the recent decades (e.g. Brandl and Maguire, 2002; Carasco and Singh, 2003; Lere and Gaumnitz, 2007; Schwartz et al., 2005). We suggest that ethical codes created in the context of one cultural pattern (whether at national, organisational or another level) are unlikely to be accepted by the employees and to be implemented if transplanted into a different cultural pattern. Only those codes of conduct that reflect the dynamic ethical preferences of the people who make up a corporation, will be meaningful and effective in the long term. Perhaps this disjunct may explain why ethical codes are often not actually followed in practice and seem to serve strategic legitimation motives rather than a real desire for organisational change (Long and Driscoll, 2008). This does, however, not mean that managers should altogether give up having any systematic stand on business ethics. What we are advocating is that ethical codes and other similar business practices and processes should be allowed to evolve and that they should be sensitive to the belief system associated with the four different solidarities if they are to be effective. In this sense, the 'living code of ethics' promoted by 
Verbos et al. (2007) would seem to be likely to be more effective if different solidarities, as discussed by CT, can be embedded in it. Another theme that emerges from the discussion presented in this article is that no one model, code or approach is applicable to all companies. Since ethical conduct is a complex process resulting from the dynamic interaction of the individual, the corporation and the environment, a one-size-fits-all solution would not work.

In this article, we have introduced the ideas of Douglasian CT into a discussion of business ethics. We believe that this is a fruitful way of considering the impact of culture on ethical decision making and business ethics more generally. More empirical and theoretical work is needed, however, to firm up the relationship between culture and business ethics. Future empirical work specifically designed for the purpose is needed to establish links between cultural patterns and approaches to business ethics with more depth and accuracy, which in turn will enable further refinement of the theoretical link between CT and business ethics.

\section{Notes}

1 http://www.sewa.org/aboutus/index.asp. Accessed on 6 March 2008.

2 http://www.financialexpress.com/news/CorporateSocial-Responsibility-The-Amul-Way/112172/1. Accessed on 28 February 2008.

3 http://www.relianceadagroup.com/adportal/ada/ careers/hr.html. Accessed on 25 September 2007.

\section{References}

Alas, R.: 2006, 'Ethics in Countries with Different Cultural Dimensions', Journal of Business Ethics 69, 237-247. doi:10.1007/s10551-006-9088-3.

Balasubramanian, N., D. Kimber and F. Siemensma: 2005, 'Emerging Opportunities or Traditions Reinforced? An Analysis of the Attitudes towards CSR and Trends of Thinking about CSR in India', JCC (Spring), 17.

Bhattacharji, S.: 1995, Fatalism in Ancient India (Baulmon Prakashan, Calcutta).

Brandl, P. and M. Maguire: 2002, 'Codes of Ethics: A Primer on Their Purpose, Development and Use', Journal for Quality and Participation 25(4), 8-12.
Carasco, E. and J. Singh: 2003, 'The Content and Focus of the Codes of Ethics of the World's Largest Transnational Corporations', Business and Society Review 108(1), 71-94.

Chakraborthy, S. K.: 1997, 'Business Ethics in India', Journal of Business Ethics 16(14), 1529-1538.

Coyle, D.: 1997, 'A Cultural Theory of Organizations', in M. Thompson and R. J. Ellis (eds.), Culture Matters: Essays in Honour of Aaron Wildavsky (Westview Press, Boulder, CO), pp. 59-78.

Coyle, D. and R. Ellis (eds.): 1994, Politics, Policy and Culture (Westview Press, Boulder, CO).

Crane, A. and D. Matten: 2007, Business Ethics, 2nd Edition (Oxford University Press, Oxford).

Davis, M., N. Johnson and D. Ohmer: 1998, 'IssueContingent Effects on Ethical Decision Making: A Cross-Cultural Comparison', Journal of Business Ethics 17, 373-389. doi:10.1023/A:1005760606745.

Douglas, M.: 1970, Natural Symbols (Barrie and Rockliffe, London).

Douglas, M.: 1978, Cultural Bias. Occasional Paper 35 (Royal Anthropological Institute, London).

Douglas, M.: 1986, How Institutions Think (Routledge and Keegan Paul, London).

Douglas, M.: 1996, Thought Styles: Critical Essays on Good Taste (Sage Publications, London).

Douglas, M. and A. Wildavsky: 1983, Risk and Culture: An Essay on the Selection of Technical and Environmental Dangers (University of California Press, Berkeley).

Elder, J.: 1966, 'Fatalism in India: A Comparison Between Hindus and Muslims', Anthropological Quarterly 39(3), 227-243. doi:10.2307/3316807.

Ferrell, O. and L. Gresham: 1985, 'A Contingency Framework for Understanding Ethical Decision Making in Marketing', Journal of Marketing 49(Summer), 87-96. doi:10.2307/1251618.

Friedman, M.: 1970, 'The Social Responsibility of Business is to Increase Its Profits', New York Times Magazine, p. 32.

Gross, J. and S. Rayner: 1985, Measuring Culture. A Paradigm for the Analysis of Social Organization (Columbia Press, New York).

Gupta, A.: 2007, 'Social Responsibility in India: Towards Global Compact Approach', International Journal of Social Economics 34(9), 637-663. doi:10.1108/0306829 0710778642 .

Hofstede, G.: 1984, Culture's Consequences - International Differences in Work-Related Values (Sage Publications, London).

Husted, B. and D. Allen: 2008, 'Toward a Model of Cross-Cultural Business Ethics: The Impact of Individualism and Collectivism on the Ethical Decision- 
Making Process', Journal of Business Ethics 82, 293-305. doi:10.1007/s10551-008-9888-8.

Jones, T.: 1991, 'Ethical Decision Making by Individuals in Organizations: An Issue-Contingent Model', Academy of Management Review 16(2), 366-395. doi:10.2307/ 258867.

Jose, P., R. Bandi and M. Mehra: 2003, 'Corporate Social Responsibility in the Information and Communication Technology Sector: Discussion', IIMB Management Review (December issue), 61-75.

Kanagasabapathi, P.: 2007, 'Ethics and Values in Indian Economy and Business', International Journal of Social Economics 34(9), 577-585. doi:10.1108/0306829071 0778606.

Kearney, A. T.: 2004, Offshore Location Attractiveness Index: Making Offshore Decisions.

Korten, D.: 1998, When Corporations Rule the World (The Other India Press, Goa).

Lere, J. and B. Gaumnitz: 2007, 'Changing Behaviour by Improving Codes of Ethics', American Journal of Business 22(2), 7-17.

Long, B. and C. Driscoll: 2008, 'Codes of Ethics and the Pursuit of Organizational Legitimacy: Theoretical and Empirical Contributions', Journal of Business Ethics 77, 173-189. doi:10.1007/s10551-006-9307-y.

Longenecker, J., C. Moore, W. Petty, L. Palich and J. McKinney: 2006, 'Ethical Attitudes in Small Business and Large Corporations: Theory and Empirical Findings from a Tracking Study Spanning Three Decades', Journal of Small Business Management 44(2), 167-183. doi:10.1111/j.1540-627X.2006.00162.x.

Lovell, A.: 2002, 'Moral Agency as A Victim of Vulnerability of Autonomy', Business Ethics. European Review (Chichester, England) 11(1), 62-76.

Mars, G.: 1982, Cheats at Work: An Anthropology of Workplace Crime (Allen \& Unwin, London).

Mathias, T. A.: n.s., Ethical Decision-Making in India. Human Action in Businesses.

McCabe, A., R. Ingram and M. Dato-on: 2006, 'The Business of Ethics and Gender', Journal of Business Ethics 64(2), 101-116. doi:10.1007/s10551-005-3327-x.

Moon, C. and P. Woolliams: 2000, 'Managing Cross Cultural Business Ethics', Journal of Business Ethics 27, 105-115. doi:10.1023/A:1006409207699.

O'Fallon, M. and K. Butterfield: 2005, 'A Review of the Empirical Ethical Decision Making Literature 19962003', Journal of Business Ethics 59, 375-413. doi:10.1007/ s10551-005-2929-7.

Patel, T.: 2005, Using Dynamic Cultural Theories to explain the Viability of International Strategic Alliances: A Focus on Indo-French Alliances. PhD Thesis, Open University. Milton Keynes, UK.
Patel, T.: 2006, Making Sense of Diversity of Ethical Strategies in Businesses: A Focus on the Indian Context. CRR Conference, Trinity College, Dublin.

Patel, T.: 2007, Stereotypes of Intercultural Management: A Dynamic Appreciation of Viability of FrenchIndian Strategic Alliances (Eburon Publishers, Delft, Holland).

Patel, T. and S. Rayner: 2008a, A Cultural Analysis of Corporate Sustainability Reporting Practices: Case Studies from India. Working Paper Series, JMI, Said Business School, University of Oxford.

Patel, T. and S. Rayner: 2008b, A Cultural Appreciation of Corporate Sustainability Reporting by Indian Companies (British Academy of Management Conference, Harrogate, UK).

Pendergraft, C.: 1998, 'Human Dimensions of Climate Change: Cultural Theory and Collective Action', Climatic Change 39(4), 643-666. doi:10.1023/A:1005 323809980.

Perry, S. and E. Peck: 2004, 'New Labour's Modernization in the Public Sector: A Cultural Theory Approach \& The Case of Mental Health Services', Public Administration 82(1), 83-108.

Prahalad, C.: 2004a, The Fortune at the Bottom of the Pyramid: Eradicating Poverty Through Profits (Pearson Education, Upper Saddle River: NJ).

Prahalad, C.: 2004b, 'Why Selling to the Poor Makes for Good Business', Fortune 150(9), 32-33.

Rayner, S.: 1982, 'The Perceptions of Time and Space in Egalitarian Sects: A Millenarian Cosmology', in M. Douglas (ed.), Essays in the Sociology of Perception (Routledge and Keegan Paul, London).

Rayner, S.: 1986, 'Management of Radiation Hazards in Hospitals: Plural Rationalities in a Single Institution', Social Studies of Science 16, 573-591. doi:10.1177/ 030631286016004002.

Resick, C., P. Hanges, M. Dickson and J. Mitchelson: 2006, 'A Cross-Cultural Examination of the Endorsement of Ethical Leadership', Journal of Business Ethics 63(4), 345-359. doi:10.1007/s10551-005-3242-1.

Rest, J.: 1986, Moral Development: Advances in Research and Theory (Praeger, New York).

Ringov, D. and M. Zollo: 2007, 'The Impact of National Culture on Corporate Social Performance', Corporate Governance: The International Journal of Effective Board Performance 7(4), 476-485.

Sankaran, K.: 2003, 'Imperatives of a Civil Corporation in the New Economy', IIMB Management Review (December Issue), 82-88.

Schepers, D.: 2006, 'Three Proposed Perspectives of Attitude towards Business' Ethical Responsibilities and Their Implications for Cultural Comparison', Business 
and Society Review 111(1), 15-36. doi:10.1111/j.14678594.2006.00259.x.

Scholtens, B. and L. Dam: 2007, 'Cultural Values and International Differences in Business Ethics', Journal of Business Ethics 75, 273-284. doi:10.1007/s10551-0069252-9.

Schwartz, M., T. Dunfee and M. Kline: 2005, 'Tone at the Top: An Ethics Code for Directors?', Journal of Business Ethics 58, 79-100. doi:10.1007/s10551-0051390-y.

Schwarz, M. and M. Thompson: 1990, Divided We Stand: Redefining Politics, Technology and Social Choice (Harvester Wheatsheaf, London).

Srnka, K.: 2004, 'Culture's Role in Marketers' Ethical Decision Making: An Integrated Theoretical Framework', Academy of Marketing Science Review 1. http:// www.amsreview.org/articles/srnka01-2004.pdf.

Steenhaut, S. and P. Kenhove: 2006, 'An Empirical Investigation of the Relationships among a Consumer's Personal Values, Ethical Ideology and Ethical Beliefs', Journal of Business Ethics 64(2), 137-155. doi:10.1007/s10551-005-5905-3.

Sundar, P.: 2000, Beyond Business: From Merchant Charity to Corporate Citizenship (Tata McGraw Hill, New Delhi).

Tenbrunsel, A. and K. Smith-Crowe: 2008, 'Ethical Decision Making: Where We've been and Where We're Going', Academy of Management Annals 2, 545607.

Thompson, M.: 1996, Inherent Relationality: An AntiDualistic Approach to Institutions (LOS Centre Publication, Bergen).

Thompson, M.: 1997a, 'Rewriting the Precepts of Policy Analysis', in M. Thompson and R. J. Ellis (eds.), Culture Matters: Essays in Honour of Aaron Wildavsky (Westview Press, Boulder, CO).

Thompson, M.: 1997b, 'Cultural Theory and Technology Assessment', in F. Fischer and M. Hajer (eds.), Living with Nature: Environmental Discourse and Cultural Politics (Oxford University Press, Oxford).

Thompson, M.: 1997c, 'Cultural Theory and Integrated Assessment', Environmental Modelling and Assessment 2, 139-150.

Thompson, M. and A. Wildavsky: 1986, 'A Cultural Theory of Information Bias in Organizations', Journal of Management Studies 23(3), 273-286.
Trevino, L.: 1986, 'Ethical Decision Making in Organisations: A Person Situation Interactionist Model', Academy of Management Review 11(3), 601-617.

Unerman, J., J. Bebbington and B. O'Dwyer (eds.): 2007, Sustainability Accounting and Accountability (Routledge, London and New York).

Usunier, J.: 1998, International \& Cross-Cultural Management Research (Sage Publications, London).

Velasquez, M.: 2002, Business Ethics: Concepts and Cases, 5th Edition (Prentice Hall, Upper Saddle River, NJ).

Verbos, A., J. Gerard, P. Forshey, C. Harding and J. Miller: 2007, 'The Positive Ethical Organization: Enacting a Living Code of Ethics and Ethical Organizational Identity', Journal of Business Ethics 76, 17-33.

Victor, B. and J. Cullen: 1987, 'A Theory and Measure of Ethical Climate in Organizations', Research in Corporate Social Performance and Policy 9, 51-57.

Vitell, S. and E. Hidalgo: 2006, 'The Impact of Corporate Ethical Values and Enforcement of Ethical Codes on the Perceived Importance of Ethics in Business: A Comparison of US and Spanish Managers', Journal of Business Ethics 64(1), 31-43.

Westerman, J., R. Beekun, Y. Stedham and J. Yanamura: 2007, 'Peers Versus National Culture: An Analysis of Antecedents to Ethical Decision Making', Journal of Business Ethics 75, 239-252.

Williamson, O.: 1975, Markets and Hierarchies: Analysis and Antitrust Implications (Free Press, New York).

Wynne, B. and H. Otway: 1982, 'Information Technology: Power and Managers', in N. Bjorn-Anderson et al. (eds.), Information Society: For Richer for Poorer (North- Holland, Amsterdam).

Taran Patel

La Rochelle Business School,

La Rochelle, France

E-mail:taran.patel@gmail.com

Anja Schaefer

Open University,

Milton Keynes, U.K. 
Copyright of Journal of Business Ethics is the property of Springer Science \& Business Media B.V. and its content may not be copied or emailed to multiple sites or posted to a listserv without the copyright holder's express written permission. However, users may print, download, or email articles for individual use. 